\title{
Research on Development of Health Tourism Products in Qinling Mountains
}

\author{
Jing-Ting ZONGa, ${ }^{\mathrm{a},}$, Jing SUN ${ }^{\mathrm{b}}$, Jian-Miao DAl and Fu-Mei Rao \\ Xi'an University, College of History and Culture, Xi'an, Shaanxi 710065, China \\ a443895095@qq.com, b79840790@qq.com
}

Keywords: health tourism, product development, Qinling Mountains

\begin{abstract}
With the continuous improvement of the living standards of the people in the country, the growing awareness of health and the transformation of tourism concepts, health tourism has become more and more popular. As a combination of tourism and health care, physical fitness, leisure and health care, health tourism has gradually developed into a key industry to promote local economic development. In recent years, with the introduction of a series of incentives and growing market demand, China's healthy tourism industry has entered a period of rapid development. Relying on abundant forests, mountains, hot springs and other resources to develop health industry will become a highlight of the development of China's health tourism industry.
\end{abstract}

\section{Introduction}

Qinling Mountains are vast in area. Mountainous areas, forests, hot springs, culture and other health tourism resources are rich and profound, environmental quality and climatic conditions are excellent, external conditions and internal conditions have absolute advantages, so the development of healthy tourism is unique. This study uses the SWOT analysis method to analyze the advantages and disadvantages, opportunities and challenges of developing healthy tourism in Qinling Mountains. Combining market development and resource advantages, this paper proposes that Qinling Mountains can develop four health tourism products: forest health, outdoor sports fitness, religious culture Zen and hot spring bath, to create an international brand of health tourism in Qinling Mountains through the combination of online and offline marketing tools.

After more than 40 years of development, China has achieved a historic leap from a tourism-scarce country to a tourist country. The tourism industry is fully integrated into the national strategic system and is at the forefront of national economic construction and has become a strategic pillar industry of the national economy. Economists predict that by 2020, China's tourism revenue will reach $6 \times 10^{10}$ billion, accounting for more than 5\% of GDP. The rapid development of China' $\mathrm{s}$ economy and the increasing competition in society,so the pressure on the people are getting heavier. According to the social survey statistics in 2016, 600 million people are in the "third state" . According to the sample survey conducted by the National People's Congress of China, the results of the survey show that: In the mean ranking of the importance of modern people's tourism motivation, the primary motivation is to relax the spirit, that is, most people release stress, relieve stress and restore healthy vitality through tourism. Among many tourism products, health tourism can perfectly integrate health and tourism. The concept of health tourism was proposed by the National Tourism Administration in 2000. Sports tourism combines physical fitness and tourism, furthermore, our country vigorously advocated a civilized and healthy way of tourism. In 2003, Xi'an, Hanzhong, and Weinan also launched tourism activities such as "healthy tourism" and “joyful health tourism”. In 2007, Wang Yan and Gao Yuanheng, who are domestic scholars, defined from the academic perspective that they can improve and improve the physical and mental health of tourists; and they divide health tourism into four types: health care, leisure adjustment, 
physical fitness and self-realization. In 2014, the National Tourism Administration and the State Administration of Traditional Chinese Medicine jointly promoted the sustainable development of TCM health tourism and added TCM medical tourism to health tourism ${ }^{1}$. According to statistics, in 2018, the number of tourists from mountainous and forestous countries in the country exceeded 1.6 billion, accounting for nearly $30 \%$ of the total number of domestic tourists, the comprehensive output value was about 15,000 yuan. Healthy tourism has gradually become the mainstream of tourism. Forums and seminars on health tourism are also Gradually expand.

\section{Healthy Tourism Health Resources in Qinling Mountains}

Qinling Mountains are a mountainous area located in the southern part of Shaanxi Province, between the Weihe River and the Han River. It is a world-class tourism resource enrichment area ${ }^{2}$, which combines diverse historical culture with both north and south scenery, so rich and colorful natural and humanistic tourism resources are highly enriched to form a super-large natural tourist attraction. Unique geology, geomorphology, climate, vegetation and culture are the background conditions for the development of healthy tourism in Qinling Mountains.

\subsection{Hot spring tourism resources}

As one of the regions with the most abundant geothermal resources in China, Qinling Mountains has abundant hot spring resources. According to statistics, there are more than 290 hot springs in the northern foot of the Qinling Mountains. The total distribution of hot spring resources is $450 \mathrm{Km}$, with an area of about $1.5 \times 103 \mathrm{Km}^{2}$, and the available reserves are nearly $44.2 \times 109 \mathrm{~m}^{3}$. The time of Hot Spring development in Qinling Mountains can be traced back to the Tang Dynasty. The Song of Everlasting Sorrow makes Huaqing Pool famous in the world. The cultural essence of Hot Spring in Qinling Mountains is profound and long-lasting. At present, the most famous hot spring bathing and healing resorts in Shaanxi are in the Qinling Mountains, and the western Tangyu of Meixian County, which is famous for its hot spring swimming, is in the western part of the hot spring formed by the piedmont break in Qinling Mountains3.

\subsection{Forest tourism resources}

As the central national park of China, Qinling Mountains have an average forest coverage rate of $57.3 \%$ and more than 14 national forest parks. The forest coverage rate of Taibai Mountain National Nature Reserve is $80.7 \%$, and the forest coverage rate of some local protected areas is over $70 \%$. The central confluence of forest carbon sinks in China and the core supply area for plant oxygen release are also in the Qinling Mountains. It is also known as the central green lung 4 and carbon sink oxygen source in China. The unique species of the Qinling Mountains are also numerous, such as: ash tree, string vine, aspen, horse hair pine, Huashan pine and so on.

\subsection{Mountain touris m resources}

Known as the dragon vein of the Chinese civilization, Qinling Mountains are the most famous

\footnotetext{
${ }^{1}$ Zhao Wen. Shaanxi province promotes the development of Chinese medicine health tourism [J]. Journal of Traditional Chinese Medicine Management, 2018, 26 (18): 10.

${ }^{2}$ Lei Huixia, Jing Bo. Study on the Strategic Development of National Central Park in Qinba Mountains [J]. China Engineering Science, 2016, $18(5): 39-45$.

${ }^{3}$ Li Wei. Rapid development of hot spring tourism in Shaanxi province . Shaanxi Media Network

[DB/OL] http://www. sxdaily. com. cn/n/2017/1221/c335-6300400. html. $2017-12-21 / 2019-3-20$.

${ }^{4}$ Yu Xiaohui, Zhou Qinghua, Liu Peidan. Analysis of the Current Policy System of Green Cycle Development in Qinba Mountain Area[J]. Ecology and Economy, 2016, 32 (6).
} 
mountain in China, as the north-south boundary line. It has a length of 1,600 kilometers. There are about 10 peaks above 3000m above sea level in the Qinling Mountains, and there are more than 30 peaks famous for outdoor sports, such as Taibai Mountain, Zhongnan Mountain, Lishan Mountain and Cuihua Mountain. There are 72 valleys in the Qinling Mountains, but 72 is only a virtual index. In the book "72 valleys in Qinling Mountains ", there are 226 valleys recorded by scholars in detail, among which the most famous ones are Laoyu valley, Qingyu valleys and Daogou valleys .

\subsection{Cultural tourism resources}

As the traceable source of Chinese culture, Qinling Mountains can be traced back to the early stage of human civilization. Qinling Mountains are the birthplace of Chinese Taoism. Laozi' s Tao Te Ching was written in the Qinling Mountains. The ancestors of the six major sects of Chinese Buddhism are in the Qinling Mountains. Jin Yong' $s$ martial arts novels have given Qinling Mountains a different legendary culture.The most classic is the Huashan sword tournament, Chongyang Palace which is Wang Chongyang' s monastic land and Quanzhenjiao' s location in Zhongnanshan Mountain. If you want to understand the religious culture, Qinling Mountains must be the first choice.

Although the health tourism resources in Qinling Mountains are diverse, the scenic spots developed in Qinling Mountains have only been part of it. There are still huge resources in the Qinling Mountains for development and exploration. Tourists do not have a clear understanding of the resources and products that have been developed. These resources and products do not make people really like and enjoy tourism resources in Qinling Mountains. It does not have much benefit to the development of tourism in Shaanxi.

\section{SWOT Analysis of Health Tourism Products IN Qinling Mountains}

The SWOT analysis is a decision-making strategic analysis method proposed by Heinz Weihrich, who is American management professor. Through the SWOT analysis method to analyze the development of health tourism products in Qinling Mountains, the comprehensive, systematic and accurate research can be carried out on the areas where health tourism products are located, so as to formulate strategies, plans and countermeasures in line with local development based on the results of analysis and research.

\subsection{Strengths analys is}

In terms of natural advantages, the development of health tourism products in the Qinling Mountains has unique health tourism resources. The types of tourism resources in the Qinling Mountains are rich and varied. Among them, the national forest parks, religious temples, and natural hot springs have been established, which are all good foundations for the development of health tourism products. In terms of national policies, the "China Sports Fitness Tour" was confirmed by the National Tourism Administration in 2010, various tourism and leisure products pointed out in 2013, China Forest Tourism Forum successfully held in 2018, and all of this shows that the country strongly promotes healthy tourism. From the consumer market, due to the population restriction policy of family planning, aged tendency of China's population is serious, while the elderly are more concerned about health and health, and this consumer group has become the main tourism consumer market for old-age care; Middle-aged people have a strong economic ability, is an 
important consumer group. The economic pressure and life pressure of this group are relatively large, so they are in a sub-health state. They want to relax and release their pressure through forest bathing, physical exercise, etc. They also want to travel and make their health more healthy through parent-child activities. Young people are in excellent condition, dare to challenge, and dare to pursue stimulation and innovation. They are the main consumer groups for outdoor adventure tourism.

\subsection{Weaknesses analysis}

However, in the area of Qinling Mountains, most of the forest parks and scenic spots have been established earlier, the infrastructure is aging, the renewal speed is slow, the management methods, management concepts and research and development levels are also relatively backward. The main employed people in the scenic spot in Qinling Mountains are local farmers, and the level of education is not high. This leads to the lack of service concept for the managers of the scenic spot, and it cannot provide perfect services for tourists, so that visitors are only a group of people in and around Shaanxi Province. Tourists are not aware of the environment during the tourism process. They messed up the items they carried, The cleaning staff in the scenic area did not dispose of the garbage in time, to cause huge environmental pollution.

\subsection{Opportunities analysis}

The healthy tourism products in Qinling Mountains are an emerging product with great potential for tourism. They combine tourism activities with medical care, outdoor activities and leisure sports perfectly. The historical and cultural resources and natural geographical resources contained in Qinling Mountains are the treasure house of tourism in Shaanxi. Such as one of the eight wonders of the world, the Terracotta Warriors and Horses of Q in Shihuang, the red city of Yanan in northern Shaanxi, the magnificent Hukou Waterfall, the beautiful southern Shaanxi town, and the Han Chang'an City and other famous scenic spots. They can form a huge tourism network, which can not only increase the rich diversity of consumers' tourism to qinling mountains, but also give consideration to the promotion of shaanxi's overall tourism industry and to promote tourism in Qinling mountains.

According to the diversified needs of tourists in today's society, it is an inevitable trend to develop tourism products that conform to the market trend. The development situation of forest health tourism products abroad is very good, and it has opened up an international market for China's health tourism products. We can learn from foreign experience, adhere to the concept of people-oriented and innovative, seize the opportunity, and make the health tourism products in Qinling mountains into an international brand and go to the world.

\subsection{Threats analysis}

In Qinling Mountains, there are some well-known brands of health tourism products. Such as the Crown Ecological Town of Ankang, Ningshan's Shangba River Provincial Tourism Resort, etc.; In other cities, there are already good development trends in health tourism products. For example, the five major health tourism products on the International Tourism Island in Hainan province, Dianchi lake International Health Community in Kunming of Yunnan province, Taiwan's new model health tourism, including health checkups, spas and sightseeing. Modern people' s spending power is generally high, and consumption and tourism concepts are changing. When there are some long holidays, When the holiday time is long, some tourists will choose to go to some tourist destinations abroad which are places of Landing visa visa exemption, such as Thailand, Nepal, Malaysia, etc.. 
This leads to the reduction of tourist resources for domestic tourism, which is not conducive to the development of tourism in Shaanxi. .

\section{Development of Health Tourism Products in Qinling Mountains}

Qinling mountains are endowed with unique health tourism resources, and its spa recuperation resources, landscape resources, cultural tourism resources, and the number of national forest parks are all in the forefront of the country. From 2000 to 2019, from sports tourism to traditional Chinese medicine tourism, the National Tourism Administration of China has paid attention to and supported health tourism. Located at the boundary between the north and the south, Qinling mountains are China's traffic fortresses. Now Xianyang Airport, Baolan high-speed railway, Xicheng high-speed railway and others, Xi'an Railway Station have opened and expanded, which makes the transportation network of Qinling Mountains more developed, and also provides more opportunities and conveniences for the healthy tourism market of Qinling Mountains. The number of tourists to big cities around Qinling Mountains, such as Xi'an, Baoji and Shangluo, is increasing day by day. Their consumer market is vast. From youth, middle age to old age, they all have high consumption willingness. Its health tourism market has great potential and provides wireless vitality for its market development. As the capital city of Shaanxi, Xi'an, the economic strength is in the top 20 in the country. According to the data of the National Bureau of Statistics, in 2017, the annual GDP of Xi'an City reached 746.985 billion yuan. And through the prediction of economists, Xi'an's economy can even reach 1.3 trillion in 2020, which can provide a strong economy for Qinling Mountains health tourism products.

The development of health tourism products in Qinling Mountains can promote the tourism and economic development of neighboring cities such as Xi'an, Hanzhong and Weinan, promote the employment of surrounding cities, stabilize the social conditions around Qinling Mountains, promote the cultural connotation and heritage in Qinling Mountains, and enhance the visibility of Shaanxi. In the development process, if we can develop according to the local economic development and social ethics, and implement the sustainable development and people-oriented development concept, we can also promote the reasonable protection of tourism resources in Qinling Mountains.

\subsection{Forest Kealth Fare}

Health tourism products are mainly for middle-aged and old people. Consumers want to relax and reduce stress through travel. They can walk, run, walk, practice yoga, Tai Chi and other ways in the Qinling Mountains forest to put themselves in the forest, relax and enjoy the quiet atmosphere of the forest, so the tourists relax and relax their body and mind through activities. The efficacy of stress detoxification will maximize the effectiveness of the recuperation and conditioning of the forest, and it will be reflected in people's health promotion and disease prevention activities. The forest in Qinling Mountains is densely forested and is called the "natural oxygen bar" . Aromatic substances in plants and ultra-high negative oxygen ion index in the air can regulate human body function, increase the amount of human immune protein, accelerate blood metabolism, and strengthen resistance.Moreover, the content of phytonicide in the Qinling Mountains forest is very high. therefore, Qinling Mountains Forest is very suitable for the development of Qinling Mountains forest bath health tourism products. In combination with the terrain and forest vegetation conditions in Qinling Mountains during development, tourist walkways in areas with suitable mountain slopes should be constructed. Placed with wooden lounge chairs, coffee table tables, hammocks and other facilities around the road, visitors will be able to enjoy the scenery Qinling Mountains and experience the unique charm of the Qinling Mountains forest during the health care process. 


\subsection{Outdoor Yports litness}

There are two consumer groups of outdoor sports tourism products. One group is a group of middle-aged and adolescents in good physical condition, the other group is a group of consumers who are in poor mental state and want to release themselves through sports, or want to strengthen their health and find stimulation in tourism. This product is suitable for selecting suitable places in Qinling Mountains forest, selecting open land, setting up large-scale sports venues and establishing forest camping bases. Different sports areas should be divided and carry out various forms of sports tourism, such as mountain climbing, mountain cycling, hiking, skiing, fishing, swimming, boating, rafting, forest hunting, forest camping and outward bound training. It not only provides high-quality sports venues for tourists, but also enables them to breathe fresh air and exercise in the forest. At the same time, tourists can improve their physical fitness, burn fat, cultivate themselves, temper their will, adjust their mentality, improve their immunity, and strengthen their physique.

\subsection{Buddhist Zen in religious culture}

The consumer groups of religious health tourism products are middle-aged and old people who love Zen culture and want to experience Zen culture and purify the soul. They want to relax their feelings and experience the inspiration of Zen culture through the practice of religious meditation in the forest mountains of the Qinling Mountains. This product selects the appropriate temple in the Qinling Mountains forest. In the protection of its original building form, bamboo, stone, trees, flowers and other ecological natural materials are used for decoration, making the temple environment simple but not dilapidated, and to create a simple but comfortable accommodation. This tour product is paired with a variety of Zen courses to allow consumers to experience Zen from both inside and outside. On the external side, from the costumes of the service staff in the temple, the voices of the monks who are playing in the temple, let the consumers feel the Zen from the visual and auditory senses. On the inner side, consumers are provided with comfortable and simple Zen culture theme costumes, as well as Zen tea, Zen, and listening to the buddhist scriptures courses. After the consumers complete all the courses, they are given to consumers with Zen cult ural tourism goods and souvenirs.

\subsection{Spa for Kealth}

The product is based on the family as the main consumer unit, meeting the various leisure and entertainment needs of the elderly, children and young and middle-aged groups. This product selects the appropriate a suitable hot spring area in the Qinling Mountains forest to build a large resort that integrates tourism, health, parenting education and recreation. According to the needs of consumers, different types of soup ponds should be constructed and set up, such as: happy children's pool, longevity pool, financial pool, physical fitness pool, etc. In addition, according to the principle of TCM health, Chinese herbal medicines can be added to the hot springs, such as blood circulation whitening pool, hydrating nourishment pool, etc. All of these enable consumers to achieve beauty and to revitalize the bones, relieve fatigue, health care and other effects, and can also contribute to family harmony and emotional communication.

\section{Product Marketing of Health Tourism in Qinling mountains}

In recent years, tourism has become an indispensable part of the public's outside activities, which has become an integral part of social and economic activities. But only let visitors feel the charm of tourism products, in order to attract tourists to the scenic experience. Therefore, the significance of tourism is truly exerted, which requires an increase in the promotion of health tourism products in 
Qinling Mountains. The marketing of health tourism products in Qinling Mountains should be combined with the consumption concepts and habits of the contemporary people, and the promotion should be carried out from the online and offline aspects to enhance the popularity and reputation of tourism products, thereby to expand the market share of health tourism products in Qinling Mountains to build a well-known health tourism brand in the province, domestic and even the world.

\subsection{Online marketing}

In terms of online marketing, health tourism products Qinling Mountains can be promoted by local and other TV stations, the Internet, and broadcasting media. Inviting some tourism TV shows,such as: "Daddy, Where to Go", "Wives' Romantic Travel", "Flowers and Teenagers", to participate in the experience of health tourism products in Qinling Mountains, using celebrity effects, increase people's curiosity about the Qinling Mountains, let more people come experience the health tourism products Qinling Mountains. A portal website for health tourism products in Qinling Mountains should be established to improve tourism guidance, which should be a convenient information consultation platform with clear and clear guidance on route transportation, accommodation, food and entertainment. Cooperation with major travel + ticketing websites should be done to set up friendship links; such as the Meituan, Ctrip, Where to go and other app, to achieve online subscription and ticket purchase and other functions. Before the arrival of the statutory holidays and the peak season of tourism, the publicity of products should be increased, for example: promotion is carried out through radio broadcasts (Himalaya, Traffic Radio, Music 988) with high listening rate and well-known social apps (micro-blog, quick-hand, tremble).

\subsection{Offline marketing}

Traditional Offline marketing model should be Promoted from newspapers and magazines, outdoor advertising, travel agencies, hotels, airport waiting areas and other places. There should be some advertisements in tourism newspapers and tourism magazines to promote the tourism image and featured tourism products of the Forest Health Tourism in Qinling Mountains. The reporters can be also invited from well-known tourism magazines to experience the products in Qinling Mountains, and and then post articles on the experience of the health tourism products on the magazines to improve the reputation and popularity of the product in the eyes of the public. Outdoor billboards should be Also set up in the surrounding expressway and car service stations near Qinling Mountains. And there should be postcards of Qinling Mountain Forest Health Tourism Products distributed to various travel agencies to promote, the travel product brochure should be Placed at star hotels, express hotels and airports. There should be Alliance with the surrounding scenic spots, mutual cooperation, maintain good relations, and use a common information exchange platform to accelerate the flow of information.

\section{Conclusion}

Healthy tourism is an integral part of modern tourism. As an important part of China's tourism resources, we must seize the opportunity, base on the actual situation of Qinling Mountains, maximize the advantages of the health tourism environment in Qinling Mountains, provide services with regional characteristics in Shaanxi, innovative development methods, and form a stable health tourism customer market. We should explore the integration of health services and tourism continuously, form a brand of healthy tourism with characteristics in Qinling Mountains, promote tourism development and economic growth in Qinling Mountains, enhance the comprehensive strength of the northwest region, increase employment opportunities in Shaanxi and surrounding 
cities, and improve people's happiness index to create a more harmonious and stable society and to build well-known tourism products within the province, outside the province, in our country and even the world.

Project Fund: Major Project of Xi'an Social Science Planning Fund "Research on the routes development and protection of ancient cultural in Xi' an section in of the northern foot of Qinling Mountains, Project Number. 18ZT02";

Xi'an Social Science Planning Fund "Research on the Spatial Distribution and Integration Development of Tourism Resources in Xi'an Area, Project Number: 2017CGWL19";

Teaching reform Project in college l-level "under the Background of Ecological Civilization, research on the Development of Health Tourism Products in Qinling Mountain Forest Funding, Project Number: DC2018055.

\section{References}

[1]Li Huifang, Yang Xiaozhong. Basic characteristics and development model of health tourism, J. Journal of West Anhui University.33(2017)122-127.

[2]Zhang Yingying, Zhao Xinxing, Meng Yanfeng.A review of domestic and international health tourism research. J. Cooperative Economy and Technology. 11 (2013): 6-8

[3]Zhu Jinyue. Research on Health Tourism Product Development-— Taking Hainan Province as an Example. J. Science and Technology Plaza.6(2016):139-143.

[4]Pan Caixia. Research on Tourism Development Strategy of Suzhou Ancient Villages. D.Suzhou Institute of Science and Technology.(2011).

[5]Wu Jing. Research on the Cost and Benefit of Ecological Tourism in Qinling Mountains. D. Beijing Forestry University. (2015).

[6]Sui Hong. Opportunities and Challenges Based on the Investigation and Analysis of the Sports Tourism Market in South Xinjiang. J. Contemporary Sports Science and Technology, 12(2017)188-190.

[7]Bai Gu.Multi-agent co-operation mode of healthy tourism innovation. J .Regional Research and Development. 2(2015) 108-114.

[8]Zhou Xiaoqin, Ming Qingzhong.Study on System of Mountain Health Tourism Product .J. Resource Development \& Market.6,(2017)33-34.

[9]Several Opinions of the State Council on Promoting the Reform and Development of Tourism.N. 31(2014).

[10]Guo Lufang, Yu Dandan.Analysis of Health Tourism. J .Journal of Beijing International Studies University 03(2015)63-66.

[11]Qi Xuemei.Design of Guangxi Coastal Health Tourism Products Based on College Students' Needs_- Taking Qinzhou College as an Example.J.Green Technology.5 (2017) 180-183.

[12]Liang Zhihua, Mao Chenglian.Under Background of "The Belt and The Road", Research on the Development of Tourism Industry in Shaanxi Province [J].China Soft Science.12(2017) 49-61. 